\title{
Pengaruh Kepemimpinan Transformasional dan Motivasi terhadap Kepuasan Kerja serta Dampaknya bagi Kinerja Karyawan Klinik
}

\author{
Deswara $^{1}$, Yusuf Arifin ${ }^{2}$ \\ 1,2Program Magister Manajemen Fakultas Pascasarjana Universitas Pasundan \\ Jln. Sumatera 41 Bandung, Jawa Barat \\ E-mail: '1dokterdeswara@gmail.com, ${ }^{2}$ yusufarifin@unpas.ac.id
}

\begin{abstract}
Abstrak
Kepemimpinan transformasional dan motivasi merupakan beberapa faktor yang mempengaruhi kepuasan kerja. Kepuasan kerja akan berdampak pada kinerja karyawan. Penelitian ini bertujuan untuk mendapatkan bukti empiris mengenai pengaruh kepemimpinan transformasional dan motivasi terhadap kepuasan kerja serta dampaknya bagi kinerja karyawan kontrak nonmedis di klinik layanan primer. Metode penelitian ini adalah analisis deskriptif dan verifikatif dengan menggunakan analisis jalur. Analisis jalur digunakan untuk menganalisis hubungan antar variabel yang bertujuan untuk mengetahui hubungan sebab akibat dan pengaruh langsung maupun tidak langsung dari beberapa variabel. Subjek penelitian adalah seluruh karyawan kontrak nonmedis pada salah satu klinik layanan primer di Cimahi, Jawa Barat, yang berjumlah 22 subjek. Pengumpulan data dilakukan menggunakan kuisioner, observasi, dan wawancara pada bulan September 20I4. Data penelitian diuji secara statistik menggunakan uji korelasi dan uji regresi logistik. Hasil penelitian ini menunjukkan bahwa kepemimpinan transformasional, motivasi, kepuasan kerja, dan kinerja mendapat penilaian baik. Kepemimpinan tranformasional memiliki pengaruh langsung yang lebih besar terhadap kepuasan kerja karyawan kontrak nonmedis. Selanjutnya, kepuasan kerja memiliki pengaruh positif terhadap kinerja karyawan kontrak nonmedis. Hasil penelitian ini diharapkan dapat memberi masukan kepada manajemen klinik agar dapat meningkatkan kepuasan kerja yang berdampak pada kinerja karyawan kontrak nonmedis.
\end{abstract}

Kata kunci: Kepemimpinan transformasional, kepuasan kerja, kinerja karyawan, klinik layanan primer, motivasi.

\begin{abstract}
Transformational leadership and motivation are factors that influence job satisfaction that will have impact on employee performance. This study aimed to obtain empirical evidence about the influence of transformational leadership and motivation on job satisfaction and its impact on the performance of nonmedical contract employees at primary care clinic. This study method was descriptive and verification analysis using path analysis. Path analysis is used to analyze the relationship between variables with the aim to determine the causal relationship and the direct or indirect influence of several variables. The subjects were all nonmedical contract employees at clinic in Cimahi, West Java, which were 22 subjects. The study was conducted in September 2014, using questionnaires, observations, and interviews. Data were analyzed using the correlation test and logistic regression test. The results indicated that transformational leadership, motivation, job satisfaction, and performance had well value. Transformational leadership had a greater direct effect on job satisfaction. Furthermore, job satisfaction had a positive influence on the employee performance. The results of this study were expected to provide suggestion to clinical management in order to increase job satisfaction which will impact on nonmedical contract employees performance.
\end{abstract}

Keywords: Employee performance, job satisfaction, motivation, primary care clinic, transformational leadership. 


\section{Pendahuluan}

Pemerintah Republik Indonesia menerapkan pola pelayanan kesehatan bagi masyarakat dengan menggunakan sistem asuransi sejak bulan Januari 2014, sesuai dengan amanat Undang-Undang Nomor 40 Tahun 2004 dan Undang-Undang Nomor 24 Tahun 2011. Sistem asuransi kesehatan tersebut diselenggarakan oleh Badan Penyelenggara Jaminan Sosial (BPJS) Kesehatan. Dalam pelaksanaan program tersebut, layanan kesehatan dilakukan secara berjenjang, yang dimulai dari layanan kesehatan tingkat pertama. ${ }^{1,2}$

Untuk layanan kesehatan tingkat pertama, layanan kesehatan diberikan oleh fasilitas layanan kesehatan primer yang ditunjuk, yaitu pusat kesehatan masyarakat (puskesmas) dan klinik layanan primer yang terdaftar sebagai mitra BPJS. Hal ini sesuai dengan Peraturan Badan Penyelenggara Jaminan Sosial Kesehatan Nomor 1 Tahun 2014, yang menyatakan bahwa fasilitas layanan kesehatan tingkat pertama meliputi puskesmas atau yang setara, praktek dokter umum dan gigi, klinik pratama, dan rumah sakit tipe D atau pratama yang setara. ${ }^{3}$

Layanan kesehatan yang diberikan oleh klinik layanan primer harus berdasarkan pada standar pelayanan medik, sesuai dengan Peraturan Menteri Kesehatan Republik Indonesia Nomor 9 Tahun 2014, yang menyatakan bahwa klinik harus memberikan pelayanan kesehatan yang efektif, aman, bermutu dan mengutamakan kepentingan pasien. ${ }^{4}$ Agar amanat peraturan tersebut terlaksana, diperlukan kinerja yang baik dari seluruh karyawan klinik layanan primer, termasuk karyawan non medis dengan status kepegawaian kontrak. Kinerja yang baik akan menghasilkan pelayanan yang baik. Pelayanan yang baik akan menciptakan kepuasan pasien, yang merupakan indikator terlaksananya pelayanan kesehatan yang optimal.

Kinerja karyawan dipengaruhi oleh kepuasan kerja. Karyawan yang merasa puas terhadap pekerjaannya akan memiliki kinerja yang baik dan tidak akan mudah untuk berpindah tempat kerja. Karyawan yang merasa puas cenderung akan lebih ramah, ceria dan responsif, sehingga lebih dihargai oleh para pelanggan. Kepuasan pegawai akan berbanding lurus dengan kontribusi mereka terhadap perusahaan. Beberapa faktor yang dapat mempengaruhi kepuasan kerja karyawan adalah kepemimpinan transformasional dan motivasi. ${ }^{5-8}$ Oleh karena itu, penelitian ini bermaksud untuk menganalisis mengenai pengaruh kepemimpinan transformasional dan motivasi terhadap kepuasan kerja serta dampaknya bagi kinerja karyawan kontrak nonmedis di klinik layanan primer.

\section{Metode}

Metode penelitian ini adalah analisis deskriptif dan verifikatif dengan menggunakan analisis jalur. Analisis jalur merupakan suatu analisis yang digunakan untuk menganalisis hubungan antar variabel yang bertujuan untuk mengetahui hubungan sebab akibat dan pengaruh langsung maupun tidak langsung dari beberapa variabel. ${ }^{9}$

Penelitian ini dilakukan pada salah satu klinik layanan primer di Kota Cimahi, Provinsi Jawa Barat, Indonesia. Klinik tersebut memberikan pelayanan kesehatan 24 jam, yang meliputi pelayanan gawat darurat, umum, gigi, persalinan dan apotek. Populasi penelitian ini adalah seluruh karyawan kontrak nonmedis yang bekerja di klinik tersebut. Seluruh subjek dalam populasi penelitian (sebanyak 22 subjek) diikutsertakan sebagai subjek penelitian ini. ${ }^{10}$

Penelitian ini dilakukan pada bulan September 2014. Pengumpulan data dilakukan dengan menggunakan kuisioner, observasi, dan wawancara. Kuisioner yang digunakan dalam penelitian ini mewakili empat variabel penelitian, yaitu: 1) kepemimpinan transformasional, 2) motivasi, 3) kepuasan kerja, dan 4) kinerja karyawan. Seluruh pertanyaan yang digunakan dalam kuisioner penelitian ini telah diuji validitas dan reliabilitas dengan 
hasil uji adalah valid dan reliabel. Setiap subjek penelitian diminta untuk menjawab pertanyaan dalam kuisioner berdasarkan skala Likert, yaitu sangat setuju, setuju, ragu-ragu, tidak setuju, dan sangat tidak setuju. ${ }^{11,12}$

Analisis hasil penelitian ini terdiri dari analisis deskriptif dan analisis verifikatif. Analisis deskriptif mengelompokkan jawaban subjek penelitian terhadap pertanyaan kuisioner cenderung setuju dan cenderung tidak setuju. Jawaban cenderung setuju meliputi jawaban sangat setuju dan setuju, sedangkan jawaban cenderung tidak setuju meliputi jawaban ragu-ragu, tidak setuju, dan sangat tidak setuju. Analisis verifikatif dilakukan dengan uji korelasi dan uji regresi logistik menggunakan program statistik berdasarkan analisis jalur seperti dapat dilihat dalam Gambar 1 berikut ini. ${ }^{11}$

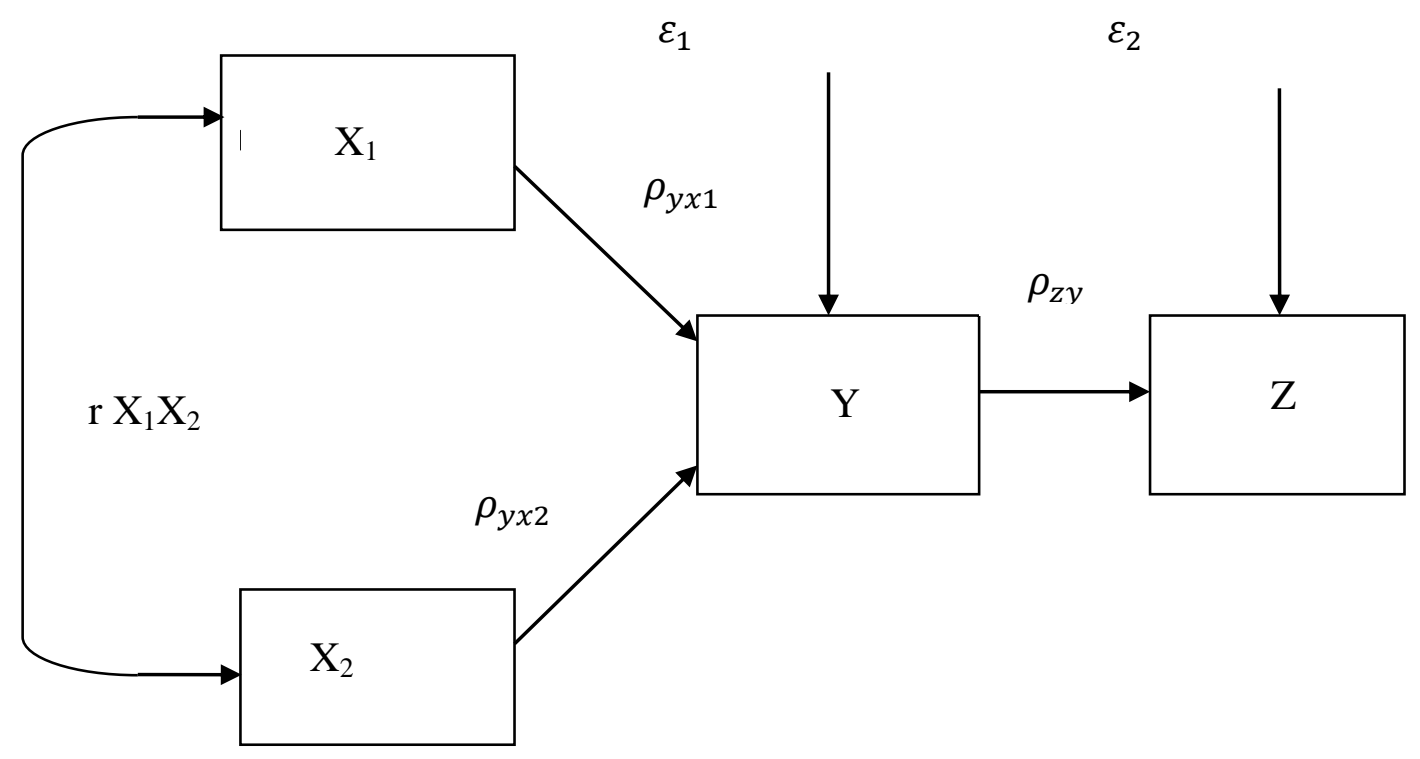

Keterangan :

Gambar 1. Diagram Jalur Analisis Verifikatif

$\mathrm{X}_{1}=$ Kepemimpinan Transformasional

$\mathrm{X}_{2}=$ Motivasi

$\mathrm{Y}=$ Kepuasan Kerja

$\mathrm{Z}=$ Kinerja Karyawan

$\rho_{y x 1} X_{1}=$ Koefisien Jalur Antara Variabel $\mathrm{X}_{1}$ dan $\mathrm{Y}$

$\rho_{y x 2} X_{2}=$ Koefisien Jalur Antara Variabel $\mathrm{X}_{2}$ dan $\mathrm{Y}$

$\rho_{z y} Y=$ Koefisien Jalur Antara Variabel Y dan Z

$\varepsilon_{1}=$ Epsilon 1, variabel lain yang tidak diteliti.

$\varepsilon_{2}=$ Epsilon 2, variabel lain yang tidak diteliti.

$\mathrm{rX}_{1} \mathrm{X}_{2}=$ Koefisien korelasi antara $\mathrm{X}_{1}$ dan $\mathrm{X}_{2}$

Persamaan Sub Struktur 1: $Y=\rho_{y x 1} X_{1}+\rho_{y x 2} X_{2}+\varepsilon_{1}$

Persamaan sub Struktur 2: $Z=\rho_{z y} Y+\varepsilon_{2}$

\section{Hasil}

Jumlah subjek penelitian ini sebanyak 22 karyawan kontrak nonmedis.
Data karakteristik subjek penelitian ini dijelaskan pada Tabel 1 berikut ini: 
Tabel 1. Data Karakteristik Subjek Penelitian

\begin{tabular}{lcc}
\hline \multicolumn{1}{c}{ Keterangan } & Jumlah Subjek & Persentase (\%) \\
\hline Jenis kelamin: & 7 & 32 \\
$\quad$ Laki-laki & 15 & 68 \\
Perempuan & & \\
Umur (tahun): & 2 & 9 \\
$\quad<20$ & 15 & 68 \\
$20-30$ & 5 & 23 \\
$>30$ & & \\
Lama bekerja (tahun): & 0 & 0 \\
$<1$ & 19 & 86 \\
$1-5$ & 3 & 14 \\
$>5$ & & 4 \\
Pendidikan: & 1 & 14 \\
Sekolah Dasar (SD) & 3 & 32 \\
Sekolah Menengah Pertama (SMP) & 7 & 36 \\
Sekolah Mengengah Atas (SMA) & 8 & 14 \\
Akademi (D3) & 3 & \\
Sarjana (S1) & & \\
\hline
\end{tabular}

Tabel 1 di atas menunjukkan bahwa subjek terbanyak berdasarkan jenis kelamin adalah perempuan, yaitu sebanyak $68 \%$. Subjek terbanyak berdasarkan kelompok umur adalah 20-30 tahun, yaitu sebanyak 68\%. Subjek terbanyak berdasarkan lama kerja adalah 1-5 tahun, yaitu sebanyak 86\%. Subjek terbanyak berdasarkan tingkat pendidikan adalah akademi (D3), yaitu sebanyak 36\%.
Untuk melihat kecenderungan subjek penelitian terhadap setiap variabel, dilakukan analisis deskriptif terhadap jawaban subjek penelitian, yang dibedakan menjadi cenderung setuju dan cenderung tidak setuju. Hasil analisis deskriptif mengenai kecenderungan setuju dan tidak setuju subjek penelitian terhadap masing masing variabel dapat dilihat pada Tabel 2 berikut ini.

Tabel 2. Kecenderungan Setuju dan Tidak Setuju Terhadap Masing-Masing Variabel

\begin{tabular}{lcc}
\hline \multicolumn{1}{c}{ Variabel } & $\begin{array}{c}\text { Cenderung setuju } \\
(\mathbf{\%})\end{array}$ & $\begin{array}{c}\text { Cenderung tidak setuju } \\
(\boldsymbol{\%})\end{array}$ \\
\hline Kepemimpinan transformasional & 61,2 & 38,8 \\
Motivasi & 69,6 & 30,4 \\
Kepuasan Kerja & 52,7 & 47,3 \\
Kinerja & 85,0 & 15,0 \\
\hline Keterangan: Cenderung setuju meliputi jawaban sangat setuju dan setuju. \\
\multicolumn{2}{c}{ Cenderung tidak setuju meliputi jawaban ragu-ragu, tidak setuju, sangat tidak setuju. }
\end{tabular}

Tabel 2 di atas menunjukkan bahwa kecenderungan setuju subjek penelitian terhadap variabel kepuasan kerja memiliki nilai persentase terendah, yaitu $52,7 \%$. Tabel 2 tersebut juga menunjukkan bahwa kecenderungan setuju subjek penelitian terhadap variabel kinerja memiliki nilai persentase tertinggi, yaitu $85 \%$.
Untuk mengetahui pengaruh kepemimpinan transformasional dan motivasi terhadap kepuasan kerja serta pengaruh kepuasan kerja terhadap kinerja dilakukan analisis verifikatif menggunakan analisis regresi. Hasil perhitungan analisis regresi terhadap variabel-variabel penelitian dapat dilihat pada Gambar 2 berikut ini. 


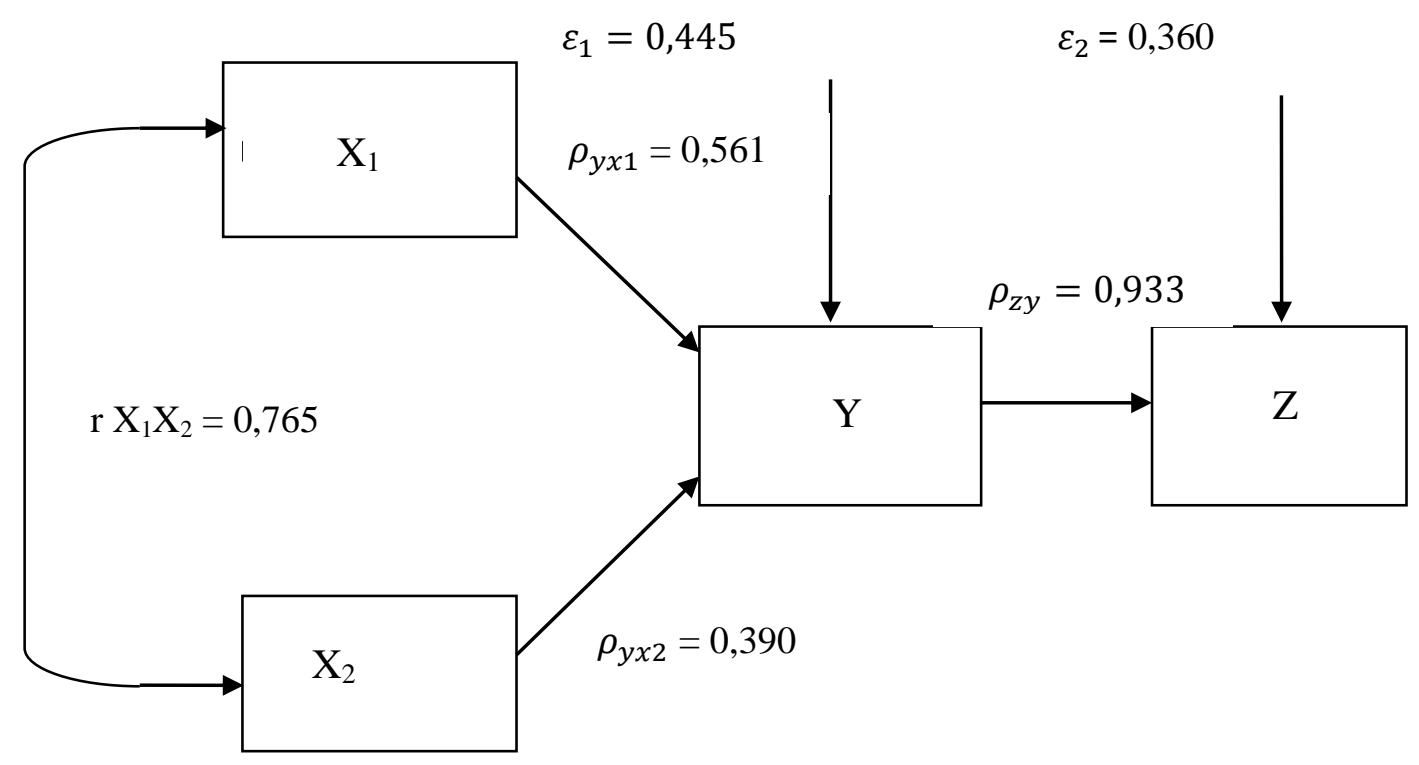

Gambar 2

Hasil Perhitungan Analisis Jalur

Berdasarkan hasil perhitungan analisis jalur tersebut, diperoleh rumus untuk menghitung pengaruh kepemimpinan transformasional dan motivasi terhadap kepuasan kerja sebagai sub struktur 1, dan pengaruh kepuasan kerja terhadap kinerja karyawan sebagai sub struktur 2. Rumus perhitungan sub struktur 1 dan sub struktur 2 tersebut adalah sebagai berikut:
Rumus Sub struktur 1: $\quad \mathrm{Y}=0,561 \mathrm{X}_{1}+$ $0,390 \mathrm{X}_{2}+0,445$

Rumus Sub struktur 2: $\quad Z=0,933 Y+$ 0,360

Berdasarkan hasil analisis verifikatif tersebut, didapatkan penilaian mengenai pengaruh langsung dan tidak langsung dari variabel-variabel penelitian. Tabel 3 berikut ini menjelaskan mengenai pengaruh kepemimpinan transformasional dan motivasi terhadap kepuasan kerja.

Tabel 3. Pengaruh Kepemimpinan Transformasional dan Motivasi terhadap Kepuasan Kerja

\begin{tabular}{lccc}
\hline \multicolumn{1}{c}{ Variabel } & Langsung (\%) & Tidak langsung (\%) & Total (\%) \\
\hline Kepemimpinan tranformasional & 31,47 & 16,74 & 48,21 \\
Motivasi & 15,21 & 16,74 & 31,35 \\
Pengaruh Total & & & 80,16 \\
\hline
\end{tabular}

Tabel 4. Pengaruh Kepuasan Kerja terhadap Kinerja Karyawan

\begin{tabular}{cc}
\hline Variabel & Pengaruh (\%) \\
\hline Kepuasan Kerja & 87,05 \\
\hline
\end{tabular}


Tabel 3 menunjukkan bahwa kepemimpinan tranformasional memiliki pengaruh langsung yang lebih besar terhadap kepuasan kerja $(31,47 \%)$, dibandingkan motivasi terhadap kepuasan kerja $(15,21 \%)$. Namun demikian, kepemimpinan transformasional dan motivasi secara simultan memiliki pengaruh langsung dan tidak langsung sebesar 80,16\% terhadap kepuasan kerja.

Berdasarkan hasil analisis verifikatif, juga didapatkan penilaian mengenai pengaruh kepuasan kerja terhadap kinerja karyawan. Tabel 4 berikut ini menjelaskan mengenai pengaruh kepuasan kerja terhadap kinerja karyawan.

Tabel 4 menunjukkan bahwa variabel kepuasan kerja memiliki pengaruh positif terhadap kinerja sebesar $87,05 \%$. Dengan demikian, pengaruh kepuasan kerja menjadi faktor intervening yang menentukan peningkatan kinerja karyawan kontrak nonmedis. Variabel intervening adalah variabel yang mempengaruhi hubungan dependen dan independen menjadi hubungan langsung dan tidak langsung yang dapat diamati dan diukur. ${ }^{11}$

\section{Pembahasan}

Hasil penelitian ini menunjukkan bahwa kepemimpinan tranformasional memiliki pengaruh langsung yang lebih besar dibandingkan motivasi terhadap kepuasan kerja karyawan kontrak nonmedis. Namun demikian, kepemimpinan transformasional dan motivasi secara simultan akan memiliki pengaruh langsung dan tidak langsung yang lebih besar terhadap kepuasan kerja. Hasil penelitian ini juga mendapatkan bahwa kepuasan kerja memiliki pengaruh positif terhadap kinerja karyawan kontrak nonmedis, yang menunjukkan bahwa semakin tinggi kepuasan kerja maka semakin tinggi kinerja.

Berdasarkan hasil analisis terhadap survey kuisioner pada penelitian ini diperoleh gambaran bahwa terdapat beberapa masalah yang berkaitan dengan kepuasan kerja yang kemudian berdampak pada kinerja karyawan kontrak nonmedis sebagaimana akan dibahas berikut ini.
Pimpinan klinik kurang memperhatikan secara khusus mengenai pengembangan karir karyawan kontrak nonmedis karena tidak ada program pelatihan dan pengembangan serta tidak tersedia jalur karir pada struktur klinik. Jabatan pada struktur klinik tidak memiliki kualifikasi dan spesifikasi yang jelas untuk karyawan kontrak nonmedis. Oleh karena itu, perlu dibuat program pelatihan dan pengembangan sumber daya manusia (SDM) yang berkaitan dengan karyawan kontrak nonmedis, serta pengembangan program dan struktur klinik. Pemimpin perlu memperhatikan kebutuhan karyawan agar mereka bisa maju dan berkembang dalam karir dan kehidupan mereka. 5,13,14

Pimpinan kurang mendorong bawahan untuk memberikan ide kreatif terhadap jawaban permasalahan yang dihadapi karyawan dan klinik. Faktor yang menyebabkan munculnya masalah tersebut adalah kurangnya waktu untuk berinteraksi dan berkomunikasi dengan pimpinan karena karyawan kontrak nonmedis lebih banyak bekerja pada jam kerja sore dan malam hari. Oleh karena itu, perlu waktu berinteraksi yang lebih lama dalam bentuk rapat yang dilakukan pada saat pergantian jam kerja. ${ }^{15,16}$

Karyawan belum percaya dan menghormati setiap kebijakan pimpinan, karena hampir tidak ada kebijakan yang memperhatikan nasib karyawan kontrak nonmedis. Sistem pengangkatan tidak jelas, tidak ada bonus dan insentif, serta gaya kepemimpinan yang terkesan ragu untuk mengambil sebuah keputusan. Pimpinan merasa tidak memiliki kewenangan dalam memberikan keputusan strategis tersebut, karena pimpinan harus selalu melaporkan dan meminta izin kepada pihak yayasan yang menaungi klinik terkait kebijakan tersebut. Oleh karena itu, perlu kewenangan yang jelas dan program yang lebih memperhatikan karyawan kontrak nonmedis selain komunikasi yang baik terhadap karyawan kontrak nonmedis. ${ }^{5,15}$ 
Karyawan belum bekerja melebihi standar pekerjaan karyawan, karena tidak ada target individu yang harus dicapai, pengarahan dari pimpinan kurang, monitoring dan evaluasi lemah, dan kurangnya motivasi dalam bekerja karena gaji dan promosi yang diberlakukan klinik dirasakan belum sesuai. Oleh karena itu, perlu dibuat kejelasan deskripsi pekerjaan dan target yang akan dicapai, monitoring dan evaluasi yang baik, serta penilaian kerja yang jelas dengan disertai penghargaan bagi karyawan yang dapat melebihi standar kerja yang telah ditetapkan. Penghargaan dapat berupa gaji dan promosi yang sesuai. ${ }^{5,15}$

Karyawan belum merasa bahwa semua rekan karyawan menghargai dan menghormati. Kemungkinan terjadi gap antara karyawan tetap dan karyawan kontrak karena terdapat perbedaan dalam pendapatan dan tunjangan serta peran dalam bidang manjerial. Terdapat kesan kelas dua pada karyawan kontrak sedikit banyak berpengaruh terhadap penghargaan antara sesama karyawan klinik. Oleh karena itu, perlu penekanan mengenai pentingnya semua peran dalam proses pelayanan, perlu dilakukan upaya untuk lebih mendekatkan interaksi antar karyawan, misalnya dengan mengadakan program rekreasi bersama, atau tidak ada pemilahan jabatan terhadap karyawan tetap maupun karyawan kontrak. ${ }^{15,17}$

Karyawan belum berusaha untuk memberikan sumbang saran dan tindakan dalam menyelesaikan permasalahan yang ada, serta belum berusaha memberikan inovasi dan kreatifitas untuk pengembangan klinik. Hal ini karena kurangnya kesempatan yang didapatkan oleh karyawan kontrak nonmedis. Karyawan kontrak nonmedis lebih banyak bekerja pada jam kerja sore dan malam hari sehingga interaksi dengan manajemen menjadi lebih sedikit. Oleh karena itu, perlu dilakukan media yang dapat menjembatani hal tersebut, misalnya dengan pembuatan majalah komunikasi atau kotak saran yang ditempatkan pada tempat tertentu. ${ }^{15,17}$

Pimpinan

mempertimbangkan usul dan saran bawahan, karena interaksi dan waktu diskusi yang sedikit dari pimpinan terhadap karyawan kontrak nonmedis. Oleh karena itu, pimpinan harus lebih banyak meluangkan waktu untuk berinteraksi dengan karyawan kontrak nonmedis agar dapat mengetahui dan mempertimbangkan segala informasi mengenai usul dan saran bawahan. ${ }^{15}$

Terdapat beberapa penelitian yang telah membahas mengenai kepuasan kerja dan kinerja karyawan dalam bidang kesehatan. ${ }^{18-20}$ Penelitian Fitrianasari, dkk. mendapatkan hasil bahwa kepuasan kerja merupakan salah satu faktor yang menentukan kinerja perawat di rumah sakit. Kepuasan kerja dan kinerja perawat di rumah sakit memiliki hubungan yang positif, yang menunjukkan bahwa semakin tinggi kepuasan kerja maka semakin tinggi pula kinerja perawat. $^{19}$ Penelitian Nanditya, dkk mendapatkan hasil bahwa kepuasan kerja tenaga kesehatan di rumah sakit dipengaruhi oleh faktor intrinsik berupa penghargaan, dan faktor ektrinsik berupa kebijakan RS, gaji dan kompensasi, lingkungan kerja, serta hubungan antara atasan dan bawahan. ${ }^{20}$

\section{Kesimpulan}

Bagi karyawan kontrak nonmedis, kepuasan kerja merupakan faktor yang memiliki nilai persentase terendah kecenderungan setuju dibandingkan kepemimpinan transformasional, motivasi, dan kinerja karyawan. Kepemimpinan tranformasional memiliki pengaruh langsung yang lebih besar terhadap kepuasan kerja karyawan kontrak nonmedis. Selanjutnya, kepuasan kerja memiliki pengaruh positif terhadap kinerja karyawan kontrak nonmedis. Terdapat beberapa permasalahan yang muncul pada karyawan kontrak nonmedis, yang meliputi pimpinan kurang memberikan dorongan kepada karyawan, gaji dan promosi yang 
diberlakukan oleh klinik dirasakan belum sesuai, dan karyawan belum memiliki kreatifitas untuk pengembangan klinik.

\section{Saran}

Saran yang dapat diajukan berdasarkan hasil penelitian ini adalah pimpinan harus meluangkan waktu untuk mendorong munculnya ide kreatif, perlu dilakukan perhitungan kembali terhadap gaji karyawan sesuai dengan kemajuan perusahaan, membuat mekanisme pengangkatan tenaga kontrak, sistem pembagian insentif dan bonus yang memadai, serta dibuat pengembangan struktur organisasi yang memberikan jalur karir yang lebih baik sebagai sarana promosi bagi karyawan kontrak nonmedis.

\section{Daftar Pustaka}

1. Undang-Undang Republik Indonesia Nomor 40 Tahun 2004 tentang Sistem Jaminan Sosial Nasional. 2004.

2. Undang-Undang Republik Indonesia Nomor 24 Tahun 2011 tentang Badan Penyelenggara Jaminan Sosial,. 2011.

3. Peraturan Badan Penyelenggara Jaminan Sosial Kesehatan Nomor 1 Tahun 2014 tentang Penyelenggaraan Jaminan Kesehatan. 2014.

4. Peraturan Menteri Kesehatan Republik Indonesia Nomor 9 Tahun 2014 tentang Klinik. 2014.

5. Robbins SP, Judge TA. Perilaku organisasi (Organizational behavior). Edisi 12. Jakarta: Salemba Empat; 2008.

6. Wibisono D. Manajemen kinerja korporasi \& organisasi: Panduan Penyusunan Indikator. Jakarta: Erlangga; 2011.

7. Wagimo, Ancok D. Hubungan kepemimpinan transformasional dan transaksional dengan motivasi bawahan di militer. Jurnal Psikologi Universitas Gadjah Mada. 2005;32(2):112-27.

8. Armstrong M. Performance management. Terjemahan Toni Setiawan. Yogyakarta: Tugu Publisher; 2004.
9. Riduwan dan Kuncoro EA. Cara menggunakan dan memaknai analisis jalur (Path Analysis). Bandung: Alfabeta; 2008.

10. Arikunto S. Prosedur penelitian suatu pendekatan praktek. Jakarta: Rinieka Cipta; 2004.

11. Ghozali. Aplikasi analisis multivariate dengan program SPSS. Semarang: Universitas Diponegoro; 2005.

12. Sugiyono. Metode penelitian administrasi. Bandung: Alfabeta; 2002.

13. Ancok D. Psychology of leadership and innovation (Psikologi kepemimpinan dan inovasi). Jakarta: Erlangga; 2012.

14. Dessler G. Manajemen sumber daya manusia. Jakarta: Salemba Empat; 2004.

15. Moorhead G, Griffin RW. Perilaku organisasi: Manajemen sumber daya manusia dan organisasi (Organizational behavior: Managing people and organizations). Jakarta: Salemba Empat;2013.

16. Bateman TS \& Snell SA. Manajemen kepemimpinan dan kolaborasi dalam dunia yang kompetitif (Management leading \& collaborating in a competitive world). 7, editor Jakarta: Salemba Empat;2009.

17. Gomes FC. Manajemen sumber daya manusia. Yogyakarta: Andi Offset; 2003.

18. Meilirianta M, Haizurrachman H. Pengaruh Pengetahuan Perawat, Ability dan Budaya Kerja terhadap Kinerja Perawat Pelaksana di Rawat Inap Rumah Sakit Umum 2 Kata Kunci Pengetahuan, Ability, budaya, kinerja perawat. ABSTRACT Daerah Al Ihsan Bandung. Jurnal Ilmiah Kesehatan. 2018;17(02):22-9.

19. Fitrianasari D, Nimran U, Utami HN. Pengaruh kompensasi dan kepuasan kerja terhadap organizational citizenship behaviour (OCB) dan kinerja karyawan. Jurnal Administrasi Bisnis. 2013;7(1):12-24.

20. Nanditya IF, Mansur M, Huda S. Faktor pembentuk kepuasan kerja tenaga kesehatan di rumah sakit. Jurnal Kedokteran Brawijaya. 2014;28(1):47-53. 